\title{
The Topic Structure of SCs
}

\author{
LIU Xiu-ying, MENG Fan-mao \\ Linyi University, Linyi, China
}

\begin{abstract}
To comprehend the syntax and semantics of small clauses (SCs) requires comprehending their topic structure. With bare infinitival complements, the subject of the SC is not the topic, which is in comparison with adjectival SCs, where the subject must be a topic. By comparing raising verbs with adjectival SC complements and raising verbs with infinitival complements, it is quite clear that the differences in the syntax and semantics of such constructions are related to whether or not the subject of the embedded clause must be a topic. Adjectival SCs have individuals as topics, while verbal SCs have events or stages. Because the subject of the adjectival SC is a topic, it can move into the matrix clause under passivization. The subject of a verbal SC is not a topic; this explains why it cannot move into the matrix under passivization.
\end{abstract}

Keywords: topic structure, small clause, syntax

\section{Introduction}

In linguistics, a small clause is a construction that has the semantic subject-predicate characteristics of a clause, but that lacks the tense of a finite clause and appears to lack the status of a constituent. The italicized strings in Example (1) exemplify two such small clauses (SCs), where the noun phrase (NP) the guard enters into a predication relation with the adjective phrase (AdjP) intelligent in (1a) and the bare stem verb phrase (VP) leave in (1b).

Example (1) (a) We consider the guard intelligent.

(b) We saw the guard leave.

The syntactic treatment of such SCs remains a matter of considerable debate. First, there is the question of constituency. Stowell $(1981,1983)$ considered that the italicized strings in Example (1) form constituents, while others, such as Williams $(1983,1994)$, do not. Second, there is the question of complex predicate formation. Some researchers maintain that the verb and the SC predicate form a complex predicate at some level of structure (Stowell, 1991). Third, there is the question of the presence or absence of functional structure. For those who do maintain that the $\mathrm{SC}$ is a constituent, there remains the question of what types of functional projections, if any, are present in such a clause. Stowell's original hypothesis about SCs considered them to be projections of a lexical head, but since then other authors have postulated various functional projections within the SC.

Those who adopt Stowell's SC approach posit similar (though not identical) syntactic structures for these SC complements and infinitival clause complements, as in Example (2).

LIU Xiu-ying, Class 3, Grade 2012, School of Foreign Languages, Linyi University. MENG Fan-mao, associate professor, master, School of Foreign Languages, Linyi University. 
Example (2) We consider [the guard to be intelligent].

In this sentence, the post-verbal NP the guard is the subject of the embedded infinitival clause. Similarly, the post-verbal NP in Example (1) is also the subject of the embedded SC. In addition, both subjects receive their Case-marking from the matrix verb. Thus, the syntax of the SCs in Example (1) is assimilated to the syntax of the exceptional Case-marking (ECM) clause in Example (2).

In a similar way, the syntax of raising verbs with an adjectival complement in (3a) is assimilated to the syntax of raising verbs with infinitival complements (3b). In both cases, the surface subject originates within an embedded clausal constituent (small or infinitival) and then raises to the matrix subject position.

Example (3) (a) The prisoner $r_{i}$ seems [ $t_{i}$ intelligent].

(b) The prisoner $r_{i}$ seems $\left[t_{i}\right.$ to be intelligent $]$.

Though certainly there are similarities between ECM/raising clauses and SCs, there are certain peculiarities of SCs that are not shared by ECM/raising clauses and have resisted a satisfactory explanation. First, while the subject of an ECM clause can raise to the matrix subject position when the matrix verb is passivized (4a), the subject of a verbal SC cannot do so (4b) (The symbol * denotes unacceptability). This is even more surprising when we realize that the subject of an adjectival small clause can $(4 \mathrm{c})$.

Example (4) (a) The prisoner is considered to be intelligent/to have left.

(b) * The prisoner was seen leave.

(c) The prisoner is considered intelligent.

These passive facts thus split SCs in two, suggesting that the syntax of verbal SCs and the syntax of adjectival SCs are quite different. Note that the lack of raising from within a verbal SC is not specific to the passive; raising never occurs with a verbal SC either. Thus, we see contrasts such as these (see Example (5)):

Example (5) (a) The prisoner seems/appears to be intelligent/to leave every day at noon.

(b) The prisoner seems/appears intelligent.

(c) * The prisoner seems/appears leave every day at noon.

Second, while raising verbs allow an adjectival SC complement, Williams (1994) observed an interpretive difference between raising verbs with an SC complement and raising verbs with an infinitival complement. With the infinitival complement, the raised subject can take both wide and narrow scope with respect to the main verb. However, with the adjectival complement, only wide scope is possible.

Example (6) (a) Children seem to be sick.

(b) Children seem sick.

Williams (1994) used these facts to argue against the idea that the subject and predicate of the SC form a constituent at some level of structure. If we accept May's (1985) analysis that the subjects of raising verbs with infinitival complements can lower back into the clause from which they originate, then it is unclear why the subject in (6b) cannot do the same, if it also involves raising from within the (small) clause. Williams proposed an analysis in which the subject of (6b) instead originates in its surface position.

An understanding of these SC peculiarities can only come from an understanding of the topic structure of these SCs. By considering what forms a topic in these SCs, we can understand why verbal SC complements do not allow raising and adjectival SC complements to raising verbs do not allow lowering. In doing so, the authors will show that (1) the matrix verb and SC predicate in some instances must form a complex predicate; (2) there is 
functional structure (specifically, Topic Phrase) within the SC; and (c) the data in Example (4) and Example (6), although pointing to differences between ECM/raising and SC constructions, do not necessarily argue against the SC hypothesis. Thus, the present analysis provides further evidence that SCs do form constituents.

\section{Distinction in Predication}

Verbal and adjectival SCs differ in more ways than part of speech. Verbal SCs involve a thetic predication, while adjectival SCs involve a categorical predication. This distinction in predication forms, developed in the 19th century by Brentano and Marty, has recently received considerable attention in linguistics (e.g., Sasse, 1987; Ladusaw, 1994; Lambrecht, 1994; Raposo \& Uriagereka, 1995). With a categorical predication form, the subject is "singled out" from the event itself, and the predicate ascribes a property to this subject. Here, the subject forms the "topic" of the clause. With a thetic predication, the subject is not singled out, but instead is introduced as one of the event participants. The thetic predication form can therefore be seen as an "event reporting" sentence that involves introducing an event into the discourse. The subject here is not a topic; in fact, such clauses are typically considered to be topicless, containing all-new information. The fact that verbal and adjectival SCs differ with respect to predication form can be demonstrated in the following way. Raposo and Uriagereka (1995), and Ladusaw (1994) observed that sentences with what Carlson (1977) called stage-level predicates involve a thetic predication, while sentences with what Carlson called individual-level predicates involve a categorical predication. What is interesting in this regard is that verbal SC complements allow only eventive, stage-level predicates, disallowing individual-level predicates such as know (see Example (7)).

Example (7) (a) The burglar saw the prisoner escape.

(b) The burglar saw the prisoner know French.

On the other hand, adjectival SC complements to verbs such as consider allow (and even require) an individual-level predicate adjective (see Example (8)).

Example (8) (a) The guard considers the prisoner intelligent.

(b) The guard judged the work acceptable.

This difference in predication is supported by the possible interpretations for the postverbal NP. Bare plural categorical subjects receive a generic interpretation, while bare plural thetic subjects can receive an existential interpretation (Ladusaw, 1994; Raposo \& Uriagereka, 1995). With a bare infinitival, the postverbal NP receives an existential interpretation (see also Felser, 1998). However, with an adjectival SC, the postverbal NP receives a generic reading. See Example (9):

Example (9) (a) The guard saw prisoners leave.

(b) The guard considers prisoners intelligent.

Thus, the difference in passive correlates with a difference in predication. Passive is possible when the embedded SC involves a categorical predication but not when it involves a thetic predication.

This conclusion is further supported by SCs that have an NP as a predicate. Nominal predicates always behave like individual-level predicates, so they always involve a categorical predication. We should expect passive to be allowed with a nominal predicate, and this is indeed the case. See Example (10):

Example (10) (a) The governor is considered [sc $t_{i}$ a fool].

(b) John was made $\left[\mathrm{sc}_{\mathrm{i}}\right.$ a linguist] (by all the hard work). 


\section{Distinctions in Subject Position}

The distinction in predication form correlates with a difference in syntactic position for the subject of these types of SCs. This should not be that surprising; Diesing $(1990,1992)$ and Kratzer (1995) established that subjects can be found either internal or external to the VP and that this correlates with the type of predicate; the subjects of stage-level predicates appear VP-internally, but the subjects of individual-level predicates appear VP-externally. Since stage-level predicates are found in sentences expressing a thetic judgment, while individual-level predicates are found in sentences expressing a categorical judgment, we should find these SC subjects in different positions. This can indeed be established by observing contrasts with respect to extraction from the SC subject.

It has long been observed that extraction from the post-verbal NP with opinion verbs is difficult. This fact has given some force to the claim that these post-verbal NPs are in subject position, since extraction from phrases in typical subject position is uniformly disallowed (Kayne, 1984; Stowell, 1991). However, what has not been so widely discussed is that extraction from the post-verbal NP with perception and causative verbs is much better. See Examples (11) and (12) (“??” in Example (11) denotes that these uttrances are less acceptable.):

Example (11) (a) ?? Which subject ${ }_{i}$ do you consider [a book about $t_{i}$ ] too boring for your class?

(b) ?? $\mathrm{Who}_{\mathrm{i}}$ did you find [a photograph of $\mathrm{t}_{\mathrm{i}}$ ] rather unattractive?

(c) ?? $\mathrm{Who}_{\mathrm{i}}$ did you judge [a rumor about $\mathrm{t}_{\mathrm{i}}$ ] false?

Example (12) (a) Which planet $t_{i}$ did you see [a picture of $t_{i}$ ] appear on your computer screen?

(b) $\mathrm{Who}_{\mathrm{i}}$ did you let [a rumor about $\mathrm{t}_{\mathrm{i}}$ ] spread around the entire department?

(c) Which president $t_{i}$ did you watch [a picture of $t_{i}$ ] burn in the wastebasket?

The subjects of adjectival SCs show a violation of the Subject Condition - subjects typically do not allow extraction. The subjects of verbal SCs, on the other hand, do not violate the Subject Condition. In this light, the subjects of verbal SCs are behaving more like objects, which allow extraction. See Example (13):

Example (13) (a) Who did [a picture of t] anger you?

(b) Who did you see [a picture of t]?

Now we must consider how the subjects of verbal SCs are like typical objects, and how the subjects of adjectival SCs are like typical subjects. If we adopt the representations in Example (14) for adjectival and verbal $\mathrm{SCs}$, in which the subject is located in different positions, we can begin to explain the differences between them.

Example (14) (a) [FP $\left.\mathrm{NP}_{\mathrm{i}}\left[\mathrm{AP}_{\mathrm{i}} \mathrm{A}\right]\right]$

(b) $\left[\mathrm{FP}\left[\mathrm{VP} \mathrm{NP}_{\mathrm{i}} \mathrm{V}\right]\right]$

With adjectival SCs, the subject has moved out of the domain of the $\theta$-role-assigning head of the SC into a functional projection (FP) associated with the SC. With verbal SCs, the subject has not moved out of the domain of the $\theta$-role-assigning head of the SC. In these representations, the subject of a verbal SC is like a typical object in that it has not moved out of the domain of the head that assigns it a $\theta$-role; similarly, the subject of an adjectival $\mathrm{SC}$ is like a typical subject in that it has moved into a functional category.

The representations above provide two ways to explain the difference in sensitivity to the Subject Condition. The subjects are different in that (1) one has moved while the other has not moved and (2) one is within the domain of the $\theta$-role-assigning head while the other is no longer within that domain. In a sense, choosing which difference to build an explanation upon involves either (1) a representational difference or (2) a derivational 
difference. Given current theoretical practice, the authors will base their explanation on (2), borrowing from Takahashi's (1994) treatment of Subject Condition violations. Takahashi (1994) gave a derivational account of Subject Condition violations by exploiting two principles developed in the Minimalist Program: Chain Uniformity and Shortest Move. See Example (15):

\section{Example (15) Chain Uniformity}

Chains must be uniform.

This condition prevents adjunction to a member of a nontrivial chain. For example, given a chain $\left(\alpha_{i}, \ldots \alpha_{n}\right)$, an element would not be able to adjoin to the head of the chain $\alpha_{i}$ because the chain would not be uniform: The head of the chain would have an adjoined element, but the rest of the chain would not. See Example (16):

\section{Example (16) Shortest Move}

Make the shortest move.

This condition requires that the landing site of a moved element be the closest asymmetrical c-commanding position for that element, relativized to the type of movement involved (an $\bar{A}$-position for $\bar{A}$-movement, an A-position for A-movement, and a head position for head movement). Takahashi remarked that with these two conditions, movement out of a subject (or any phrase) that has moved will not be possible, while movement out of a subject (or any phrase) that stays in situ will be possible, since the former movement will violate either Chain Uniformity or Shortest Move. To see why this is so, consider Example (17). Here, a subject phrase has moved out of the VP into a higher functional projection.

Example (17) [IP NP [vp $t_{i}$ V]]

Movement of the wh-phrase contained within the subject must adjoin to the subject determiner phrase (DP); this adjunction site is the closest c-commanding $\bar{A}$-position. However, because the subject has moved out of the VP, adjunction to the subject DP violates Chain Uniformity, and the sentence is ruled out. If the wh-phrase moves without adjoining to DP, Shortest Move is violated and the sentence again is ruled out. However, if the subject remains within the VP without moving, then the wh-phrase can adjoin to the subject DP without violating Chain Uniformity.

This analysis immediately carries over to explain the difference in extraction from subjects of verbal and adjectival SCs, if we consider that the subjects of the former remain in situ and the subjects of the latter move. Because the subject of an adjectival SC has moved, the wh-phrase contained inside it cannot be extracted without violating either Chain Uniformity or Shortest Move, as discussed above. Since the subject of a verbal SC remains inside the VP, extraction does not violate Chain Uniformity if the wh-phrase adjoins to the subject. Takahashi recognized that there are two alternative derivations that might allow extraction from subjects that have been moved. In the first derivation, the extraction of the wh-phrase takes place first, before the subject has moved. Because the subject has not moved, the wh-phrase can adjoin to it without violating Chain Uniformity. The wh-phrase then moves on to complementizer phrase (CP), and the subject moves out to inflection phrase (IP). See Example (18):

Example (18) (a) [CP[IP[VP[NP $\left.\left.\left.\left.\mathrm{wh}_{\mathrm{i}}\left[\mathrm{NP} \ldots \mathrm{t}_{\mathrm{i}} \ldots\right]\right] \mathrm{V}\right]\right]\right]$

(b) $\left[\mathrm{CP} \mathrm{wh}_{\mathrm{i}}\left[\mathrm{IP}\left[\mathrm{VP}\left[\mathrm{NP} \mathrm{t}_{\mathrm{i}}\left[\mathrm{NP} \ldots \mathrm{t}_{\mathrm{i}} \ldots\right]\right] \mathrm{V}\right]\right]\right]$

(c) $\left[\mathrm{CP} \mathrm{Wh}_{\mathrm{i}}\left[\mathrm{IP}\left[\mathrm{NP} \mathrm{t}_{\mathrm{i}}\left[\mathrm{NP} \ldots \mathrm{t}_{\mathrm{i}} \ldots\right]_{\mathrm{j}}\left[\mathrm{VP} \mathrm{t}_{\mathrm{j}} \mathrm{V}\right]\right]\right]\right.$

This does not violate Chain Uniformity, because under the copy theory of movement, once the subject 
moves and leaves behind a copy, both the head and the tail of the chain have something adjoined to them. However, this derivation is ruled out because it is not cyclic; the landing site for movement of the subject, which occurs second, is lower than the landing site for movement of the wh-phrase, which occurs first.

A second possible derivation is like the previous one in that the wh-phrase adjoins to the subject before it has moved, but unlike the previous one in that it is cyclic. In this derivation, after the wh-phrase adjoins to the subject, the subject moves out to its functional projection. Then the wh-phrase moves to CP.

Thus, we see how adopting a difference in the position of subjects of verbal and adjectival SCs allows us to explain the difference in extraction between verbal and adjectival SC subjects.

\section{Distinctions in Topic}

Why is there such a distinction in the position of the SC subject? Recall that the adjectival SC involves a categorical predication while the verbal SC involves a thetic predication. With a categorical predication, recall that the subject is singled out from the predicate. This subject becomes the topic of the clause, or what the clause is about. With a thetic predication, on the other hand, the subject is not singled out; it is not the topic of the clause. The difference in the positioning of the subject then correlates with whether or not the subject is the topic of the SC, or what the SC is about. With adjectival SCs, which involve a categorical predication, the subject is the topic of the predication. In such a case, the subject is raised out of the lexical head of the SC to become the topic. The claim here is that, in this case, the subject of the adjectival SC occupies a distinct topic position. With verbal SCs, on the other hand, the subject does not form a topic. For these SCs, the subject is not raised into a distinct topic position. Raposo and Uriagereka (1995) considered that there is a functional F position in which the topic of the clause resides. Given the above contrast, the subject of the adjectival SC would reside in the specifier of this F position. For concreteness, the authors will take this function projection to be Topic Phrase (TopP). If the subject of the adjectival SC is located in the specifier of TopP, then it is located outside the projection of the adjective, accounting for the syntactic effects noted above. But what about verbal SCs, which involve a thetic predication and whose subject is not in a topic position? Here, the subject is inside the VP; it does not raise into TopP. But do such clauses project a TopP? It is generally assumed that thetic clauses are topicless. However, a number of authors suggested that thetic clauses have topics. Raposo and Urigereka (1995) claimed that with a thetic predication, the entire predicate becomes what the sentence is "about", and hence the topic of the clause. In such sentences, auxiliaries function as topic markers. Jäger (1996) came to a similar conclusion. He noted that a thetic clause in a conditional statement can act as the restrictor for an adverb of quantification; in these cases, the quantification is over temporal slices. See Example (19):

Example (19) (a) If SNOW is falling, it is usually winter.

(b) usually $y_{t}$ [snow fall' (t)] [winter' (t)]

Following Chierchia (1992), he notes that the topic of such a clause provides the restriction for an adverb of quantification. If thetic clauses can act as restrictions, then there must be some element that is the topic of the clause to provide the restriction for the adverb of quantification. He concludes that thetic clauses contain a functional element - perhaps Tense - that acts as the topic.

Others have suggested that it is the "event", "situation", or "spatiotemporal" argument of the verb that functions as either an external argument (Kratzer, 1995; Ramchand, 1997) or a topic (Erteschik-Shir, 1997). Thus, 
there seems to be a consensus that thetic sentences have a topic. In this paper, the authors will adopt Erteschik-Shir's notion of stage topic.

If such sentences have a semantic topic, then it is reasonable to suppose that this semantic topic has a syntactic representation. We could consider that Tense or some other verbal functional element is the topic of such sentences, but a problem arises when we look at verbal SCs. An important characteristic of these SCs is that they lack any sort of verbal functional element; they do not occur with any tense marking, modals, or auxiliaries. See Example (20):

Example (20) (a) * The policeman saw the prisoner left.

(b) * The policeman saw the prisoner can leave.

(c) ?? The policeman saw the prisoner be arrested.

(d) * The policeman saw the prisoner be leaving.

If these SCs have topics, it is unlikely that there is some verbal functional element that acts as the syntactic representation of such a topic.

Instead, the authors suggest that there is a null pronominal element that functions as the stage topic for this SC. This null topical element provides the predication base, the entire verbal SC being predicated of it. Here, it will be the spatiotemporal (event) argument that is the topic, expressed in the syntax as pro, with the verbal SC acting as a property for the stage topic and supplying its predicate.

The differing structures for adjectival and verbal SCs are thus as follows. Note that pro has an index $t$, which gives the time and location of the stage.

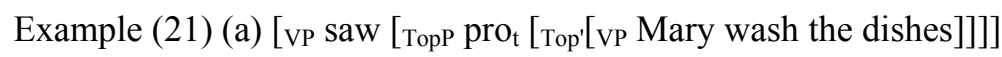

(b) [vp consider [TopP Mary [Top' $\left[\mathrm{AP}_{\mathrm{i}} \mathrm{t}_{\text {intelligent]]]] }}\right.$

With the verbal SC, the VP forms a predicate of events for a stage topic. With the adjectival SC, the AP forms a predicate of individuals for an individual topic. In (21a), the VP denotes the set of events in which Mary washes the dishes, while in (21b), the AP denotes the set of individuals who have the intelligence property.

\section{Conclusion}

Although the disparate restrictions found in verbal and adjectival SCs may appear to be the result of independent properties, these restrictions are tied to the same basic phenomenon - that of topic placement. Adjectival SCs have individuals as topics, while verbal SCs have events or stages. Because the subject of the adjectival SC is a topic, it can move into the matrix clause under passivization. The subject of a verbal SC is not a topic; this explains why it cannot move into the matrix under passivization. The notion that SCs do form constituents can be maintained if we consider the topic structure of SCs. In addition, this paper suggests that all clauses have a topic. Clauses that express thetic judgments are not topicless. A topic is present, but it is not an individual; rather, it is an event or stage. Moreover, this event or stage topic is present in the syntactic representation. Its presence is what prevents passive from occurring with passive or causative verbs with an SC complement.

\section{References}

Baltin, M., \& Collins, C. (Eds.). (2000). The handbook of contemporary syntactic theory. Oxford: Blackwell.

Belletti, A. (1988). The case of unaccusatives. Linguistic Inquiry, 19, 1-34.

Bowers, J. (1993). The syntax of predication. Linguistic Inquiry, 24, 591-656. 
Büring, D. (1997). The meaning of topic and focus - The 59th street bridge accent. London: Routledge.

Carlson, G. N. (1977). Reference to Kinds in English (Doctoral dissertation). University of Massachusetts, Amherst.

Chierchia, G. (1992). Anaphora and dynamic binding. Linguistics and Philosophy, 15, 111-183.

Chierchia, G., \& Turner, R. (1988). Semantics and property theory. Linguistics and Philosophy, 11, 261-302.

Chomsky, N. (1965). Aspects of the theory of syntax. Cambridge, Mass: MIT Press.

Collins, C. (1994). Economy of derivation and the generalized proper binding condition. Linguistic Inquiry, 25, 45-62.

Diesing, M. (1990). The syntactic roots of semantic partition (Doctoral dissertation). University of Massachusetts, Amherst.

Diesing, M. (1992). Indefinites. Cambridge, Massachusetts: The MIT Press.

Dowty, D. (1991). Thematic proto-roles and argument selection. Language, 67, 547-619.

Erteschik-Shir, N. (1997). The dynamics of focus structure. Cambridge: Cambridge University Press.

Felser, C. (1998). Perception and control: A minimalist analysis of English direct perception complements. Journal of Linguistics, 34, 351-385.

Fox, D. (1999). Reconstruction, binding theory, and the interpretation of chains. Linguistic Inquiry, 30, 157-196.

Green, G. (1974). Semantics and syntactic regularity. Bloomington: Indiana University Press.

Higginbotham, J. (1985). On semantics. Linguistic Inquiry, 16, 547-594.

Huang, C. T. J. (1993). Reconstruction and the structure of VP: Some theoretical consequences. Linguistic Inquiry, 24, $103-138$.

Jäger, G. (1996). Topics in dynamic semantics (Doctoral dissertation). Humboldt University, Berlin.

Kayne, R. (1984). Connectedness and binary branching. Dordrecht: Foris.

Kratzer, A. (1995). Stage level and individual level predicates. In G. Carlson \& F. J. Pelletier (Eds.), The generic book (pp. 125-175). Chicago: University of Chicago Press.

Ladusaw, W. A. (1994). Thetic and categorical, stage and individual, weak and strong. Proceedings of Semantics and Linguistic Theory, 4, 220-229.

Lambrecht, K. (1994). Information structure and sentence form. Cambridge: Cambridge University Press.

May, R. (1985). Logical form: Its structure and derivation. Cambridge, Mass.: MIT Press.

Pollock, J. Y. (1989). Verb movement, universal grammar, and the structure of IP. Linguistic Inquiry, 20, 365-424.

Ramchand, G. (1997). Aspect and predication: The semantics of argument structure. Oxford: Clarendon Press.

Raposo, E., \& Uriagereka, J. (1995). Two types of small clauses (toward a syntax of theme/rheme relations). In A. Cardinaletti \& M.

T. Guasti (Eds.), Syntax and semantics, 28: Small clauses (pp. 179-206). San Diego, Calif.: Academic Press.

Roberts, I. (1997). Restructuring, head movement, and locality. Linguistic Inquiry, 28, 423-460.

Rosen, S. T. (1990). Argument structure and complex predicates. New York: Garland.

Rothstein, S. (1999). Fine-Grained structure in the eventuality domain: The semantics of predicative adjective phrases and be. Natural Language Semantics, 7, 347-420.

Rothstein, S. (2001). Predicates and their subjects. Dordrecht: Kluwer.

Sasse, H.-J. (1987). The thetic/categorical distinction revisited. Linguistics, 25, 511-580.

Stowell, T. (1981). Origin of phrase structure (Doctoral dissertation). Cambridge, Massachusetts: The MIT Press.

Stowell, T. (1983). Subjects across categories. The Linguistic Review, 2, 285-312.

Stowell, T. (1991). Small clause restructuring. In R. Freidin (Ed.), Principles and parameters in comparative grammar (pp. 182-218). Cambridge, Mass.: MIT Press.

Stowell, T. (1995). Remarks on clause structure. In A. Cardinaletti \& M. T. Guasti (Eds.), Syntax and semantics, 28: Small Clauses (pp. 271-286). San Diego, Calif.: Academic Press.

Takahashi, D. (1994). Sluicing in Japanese. Journal of East Asian Linguistics, 3, 265-300.

Williams, E. (1983). Against small clauses. Linguistic Inquiry, 14, 287-308.

Williams, E. (1994). Thematic structure in syntax. Cambridge, Massachusetts: The MIT Press. 